\title{
PKCס is essential for Dishevelled function in a noncanonical Wnt pathway that regulates Xenopus convergent extension movements
}

\author{
Noriyuki Kinoshita, ${ }^{1}$ Hidekazu Iioka, Akira Miyakoshi, and Naoto Ueno \\ Department of Developmental Biology, National Institute for Basic Biology; Department of Molecular Biomechanics, \\ The Graduate University for Advanced Studies, Myodaiji, Okazaki, Aichi 444-8585, Japan
}

\begin{abstract}
Protein kinase C (PKC) has been implicated in the Wnt signaling pathway; however, its molecular role is poorly understood. We identified novel genes encoding $\delta$-type PKC in the Xenopus EST databases. Loss of PKCo function revealed that it was essential for convergent extension during gastrulation. We then examined the relationship between PKC $\delta$ and the Wnt pathway. PKC $\delta$ was translocated to the plasma membrane in response to Frizzled signaling. In addition, loss of PKC $\delta$ function inhibited the translocation of Dishevelled and the activation of c-Jun N-terminal kinase (JNK) by Frizzled. Furthermore, PKC $\delta$ formed a complex with Dishevelled, and the activation of PKC $\delta$ by phorbol ester was sufficient for Dishevelled translocation and JNK activation. Thus, PKC $\delta$ plays an essential role in the Wnt/JNK pathway by regulating the localization and activity of Dishevelled.
\end{abstract}

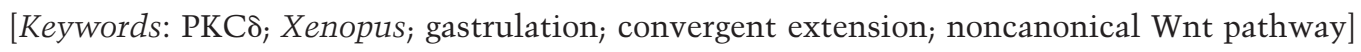

Received April 4, 2003; revised version accepted May 1, 2003.

During Xenopus gastrulation, mesodermal cells migrate to the inside of the embryo and move along the blastocoel roof. This movement is essential for embryonic morphogenic processes such as the establishment of the three germ layers and body axes. The process involves highly integrated cell movements. One of the important mechanisms for this movement is convergent extension. As convergent extension begins, cells are polarized and aligned mediolaterally; this is followed by the intercalation of these polarized cells. This movement elongates the mesodermal tissue along the anteroposterior axis, producing a driving force for gastrulation movements (Wilson and Keller 1991; Shih and Keller 1992; Wallingford et al. 2002). The regulation of the convergent extension movements is known to involve a noncanonical Wnt signaling pathway.

The Wnts are a family of secreted proteins that regulate many biological processes (Cadigan and Nusse 1997). Functional analyses in Xenopus suggest that the Wnt family can be divided into two functionally distinct groups. The first group of Wnts induces a secondary axis when ectopically expressed in embryos. They activate the canonical Wnt/ $\beta$-catenin pathway and induce the

${ }^{1}$ Corresponding author.

E-MAIL nkinoshi@nibb.ac.jp; FAX 81-564-55-7571.

Article and publication are at http://www.genesdev.org/cgi/doi/10.1101/ gad.1101303. transcription of target genes such as siamois and Xnr3 (Brannon and Kimelman 1996; Carnac et al. 1996; McKendry et al. 1997). The second group of Wnts, which includes Xwnt5a and Xwnt11, activates the noncanonical Wnt signaling pathway that controls morphogenetic cell movements (Kuhl 2002; Tada et al. 2002). It was shown in zebrafish that mutations in Wnt11/silberbrick and Wnt5a/pipetail inhibit normal gastrulation movements (Rauch et al. 1997; Heisenberg et al. 2000). The noncanonical Wnt pathway branches into two cascades. One is the Wnt/JNK pathway, which involves c-Jun Nterminal kinase (JNK; Boutros et al. 1998; Yamanaka et al. 2002). The other is the Wnt/ $\mathrm{Ca}^{2+}$ pathway (Kuhl et al. 2000). In Drosophila, the Wnt/JNK pathway is called the planer cell polarity (PCP) pathway, and it specifies cell polarities in epithelial cells and other types of cells (Adler 2002).

The Wnt signaling pathway is mediated by a seventransmembrane Wnt receptor, Frizzled, and the signal is transmitted through a cytoplasmic protein, Dishevelled (Dsh), which plays pivotal roles in both the canonical and noncanonical Wnt pathways (Boutros and Mlodzik 1999; Wharton 2003). In Drosophila, Dsh localizes to the membrane, and this localization is required for Dsh function (Axelrod 2001). Xenopus Dsh (Xdsh) is also translocated from the cytoplasm to the plasma membrane in response to a signal generated by some Frizzled receptors (Yang-Snyder et al. 1996; Axelrod et al. 1998; 
Rothbacher et al. 2000). One such receptor is Xenopus Frizzled7 (Xfz7), which is involved in the noncanonical Wnt pathway (Djiane et al. 2000; Medina and Steinbeisser 2000; Medina et al. 2000). However, the mechanism of this translocation and the activation of Dishevelled is not known. The signal transduction of the canonical pathway seems to be different from that of the noncanonical pathway, because the membrane translocation of Xdsh is not required for the activation of the canonical Wnt pathway (Rothbacher et al. 2000).

Protein kinase $\mathrm{C}(\mathrm{PKC})$ is thought to be involved in the noncanonical Wnt signaling pathway, particularly in the Wnt/Ca ${ }^{2+}$ pathway, for several reasons. Xwnt5a and rat Frizzled2 activate the phosphatidylinositol pathway and increase the intracellular $\mathrm{Ca}^{2+}$ levels in zebrafish embryos (Slusarski et al. 1997a,b). The phosphatidylinositol pathway and $\mathrm{Ca}^{2+}$ levels are closely related to PKC activation. In fact, overexpression of Frizzled causes the translocation of epitope-tagged PKC $\alpha$ from the cytoplasm to the plasma membrane in Xenopus embryos (Sheldahl et al. 1999; Medina et al. 2000). Kuhl et al. (2001) showed that PKC $\alpha$ phosphorylated Dsh in vitro. In addition, the loss of $X f z 7$ function leads to a defect in tissue separation during Xenopus gastrulation, which is rescued by the overexpression of PKC $\alpha$ (Winkbauer et al. 2001). PKC is also implicated in the Xwnt11 signaling pathway for Xenopus cardiogenesis (Pandur et al. 2002) and in the Dwnt4 pathway for Drosophila ovarian morphogenesis (Cohen et al. 2002).

Although much evidence suggests that PKC is involved in the Wnt signaling pathway, the molecular roles of PKC in this pathway are not well understood. The PKC family is subdivided into three subfamilies: the classical, novel, and atypical PKCs (cPKC, nPKC, and aPKC, respectively). cPKC is activated by $\mathrm{Ca}^{2+}$ and diacylglycerol (DAG), nPKC is activated by DAG but not by $\mathrm{Ca}^{2+}$, and aPKC is not activated by these molecules (Kikkawa et al. 1989; Bell and Burns 1991; Nishizuka 1995; Newton 1997). In Xenopus, cDNAs encoding PKC $\alpha$ and PKC $\beta$, which belong to the cPKC subfamily, have been isolated (Chen et al. 1988), and shown to be involved in neural induction (Otte et al. 1988; Otte and Moon 1992). However, their roles in the regulation of gastrulation movements are not clear. Thus, we searched for novel PKC genes that might have roles in the noncanonical Wnt signaling pathway. Here, we describe the identification and functional analyses of Xenopus $\mathrm{PKC} \delta$, which belongs to the nPKC subfamily. We demonstrate that $\mathrm{PKC} \delta$ is essential for convergent extension, and that PKC $\delta$ regulates the function of Dishevelled in the Wnt/ JNK pathway.

\section{Results}

$\mathrm{PKC} \delta$ is expressed during Xenopus embryogenesis

Although PKC has been implicated in the noncanonical Wnt signaling pathway, its molecular role is poorly understood. It has been shown that Xwnt5a and rat Frizzled 2 trigger the phosphatidylinositol pathway and induce an increase in intracellular $\mathrm{Ca}^{2+}$ (Slusarski et al. 1997a,b). Among the PKC subfamilies, cPKC and nPKC are known to be activated by $\mathrm{Ca}^{2+}$ and/or diacylglycerol (DAG). For this reason, we searched our Xenopus EST database (NIBB XDB, http://Xenopus.nibb.ac.jp) to identify PKC family members that belong to the cPKC or nPKC subfamily. We found that in addition to PKC $\alpha$ and $P K C \beta$, which have already been reported (Chen et al. 1988), the database included two novel cDNAs encoding nPKC family members. The predicted amino acid sequences of these two PKCs had 95\% identity, suggesting that these are duplicated genes due to the tetraploidism of Xenopus laevis. As described later, these two genes had indistinguishable activities in the tests we performed. These proteins are the most similar to mammalian $\delta$-type PKC (Fig. 1A,B). Thus, we designated these

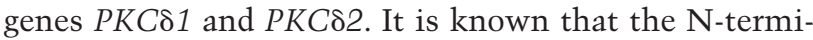
nal regulatory domain of PKCs inhibits the kinase activity by masking the catalytic domain, and activators such as DAG release this autoinhibition by binding to the $\mathrm{C} 1$ domain (Kemp et al. 1994; Orr and Newton 1994; Nishizuka 1995; Newton 1997). The regulatory domain of Xenopus PKC $\delta 1 / 2$, including the $\mathrm{C} 1$ domain, is highly homologous to that of human $\mathrm{PKC} \delta$, suggesting that these regulatory mechanisms are conserved. PKC $\delta$ is relatively similar to $\mathrm{PKC} \theta$ and $\mathrm{PKC} \varepsilon$, which also belong to the nPKC family. This class of PKCs is found not only in vertebrates, but also in sea sponges (GenBank accession no. CAA73557), Aplysia (GenBank accession no. 16975), Hydra (GenBank accession no. CAA72926), Drosophila (GenBank accession no. NP_511171), and nematodes (GenBank accession no. NP_499860). Thus, the nPKCs may have evolutionally conserved regulatory mechanisms and functions distinct from those of other PKC subfamilies.

To determine the expression patterns during Xenopus development, we performed reverse transcriptase PCR (RT-PCR) using primers whose sequences were common to $P K C \delta 1$ and $P K C \delta 2$. As shown in Figure $1 \mathrm{C}, P K C \delta$ was expressed from the two-cell stage through the tadpole stage. In situ hybridization using probes for $P K C \delta 1$ and $P K C \delta 2$ revealed that they were ubiquitously expressed (Fig. 1D). PKC $\delta 1$ and $P K C \delta 2$ were strongly expressed in the mesoderm and ectoderm during gastrulation, indicating their possible involvement in the regulation of gastrulation movements.

Overexpression of PKC lacking the catalytic domain inhibits gastrulation movements

To test whether PKC $\delta$ is involved in the regulation of gastrulation movements, we made an expression construct for PKC $\delta 1$ lacking the catalytic domain $(P K C \delta \Delta C)$. The N-terminal regulatory domain of PKCs includes pseudosubstrate and C1 domains. The pseudosubstrate domain interacts with the kinase domain and inhibits the catalytic activity (Kemp et al. 1994; Orr and Newton 1994). The C1 domain interacts with DAG and other activators. A mutant lacking the catalytic domain was 
A frog MSPFLRISFN SFDLGGMLSP SDHNQPFCAV RVKESSTTER GKTLVQKKPT
human MAPFLRIAEN SYELGSLAE DEANOPFCAV KMKEALSTER GKTLVQKKPT

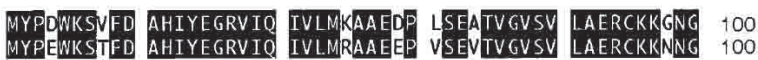
RSEFWLDLOP QAKVLMSVQY FLEDADLKQS IR-EDEGLVT INKRRGAIKQ
WAEFWLDLOP DAKVLMSVOY FLEDVDCKOS MRSEDEAKFP TMNRRGAIKO
FLE AKIHYIKNHE FTATFFGQPT FCSVCREFVM GLNKQGYKCR QCNAAIHKKC 199 AKIHYIKNHE EIATFFGOPT FCSVCKDEVW GLNKOGYKCR OCNAAIHKKC 200 IDKIIGRCTG TAANSRDTVF RKERFNIDMP HRFKVYNYKKS PTFCDHCGSL 249 IDKIIGRCTG TAANSRDTIE OKERFNIDMP HRFKVHNYMS PTFCDHCGSL 250 C1 domain

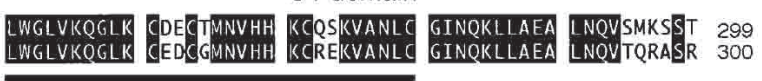
RKSDSGLDNI ATYOGVGPK- VPGLPVPNAP DNOYD/KLWEG ITPHPHISLS 348 ESDSASSEPV GIYOGFEKLT GVAGEDMQDN SGTYGLILIWE -...-S 341 SRLKIIDNFIF HKVLGKGSF KVIAEIKGK GEYFAVIKALK KDVVLIDDDV 398
SKCNINNFIF HKVLGKGSE KVLLGELKGR GEYSAIKALK KDVVLIDDDV 391 ECTMVEKRVL ALANENPFLT MVHCTFQTKE HLFFVMEFLN GGDLMFHIQD
ECTMVEKRVL TLA KGRFDLYRAT FYASETICGL RFIHSKGIIY RDL KLDNVML DRDGHIKIAD 498
KGRFELYRAT FYAAEIMGGL QFLHSKGIIY ROLKLDNVLL DRDGHIKIAD 491 FGMCKENYG DNKASTFCGT PDYIAPEILO GLKYTFSVDW WSFGVLLYEM 548
EGMCKENIFG ESRASTFCGI PDYIAPEILO GLKYTFSVDW WSFGVLLYEM 541 LIGQSPFHGD DEDELFESIR ODTPHYPRWI TKESKDILEK FFERDPFFRL 598 GVVGNIRLHP FFKTINWTAL ERRELDPPFK PKVKSPSDYS NFDREFLSEK 648
GMTGNIKIHP FFKTINWTLL EKRRLEPPFR EKVKSPRDYS WFDOEFLNEX 641

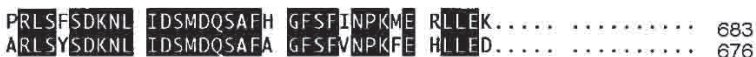

50

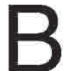
50

B (1)}

\begin{tabular}{llll}
\hline & \multicolumn{3}{c}{ identities with xPKC delta1 (\%) } \\
\cline { 2 - 4 } PKCs & whole & regulatory & catalytic \\
\hline PKC delta & $\mathbf{8 1}$ & $\mathbf{7 7}$ & $\mathbf{8 7}$ \\
PKC theta & 67 & 59 & 74 \\
PKC epsilon & 43 & 28 & 56 \\
PKC eta & 43 & 29 & 56 \\
PKC beta & n.d. & n.d. & 58 \\
\hline
\end{tabular}
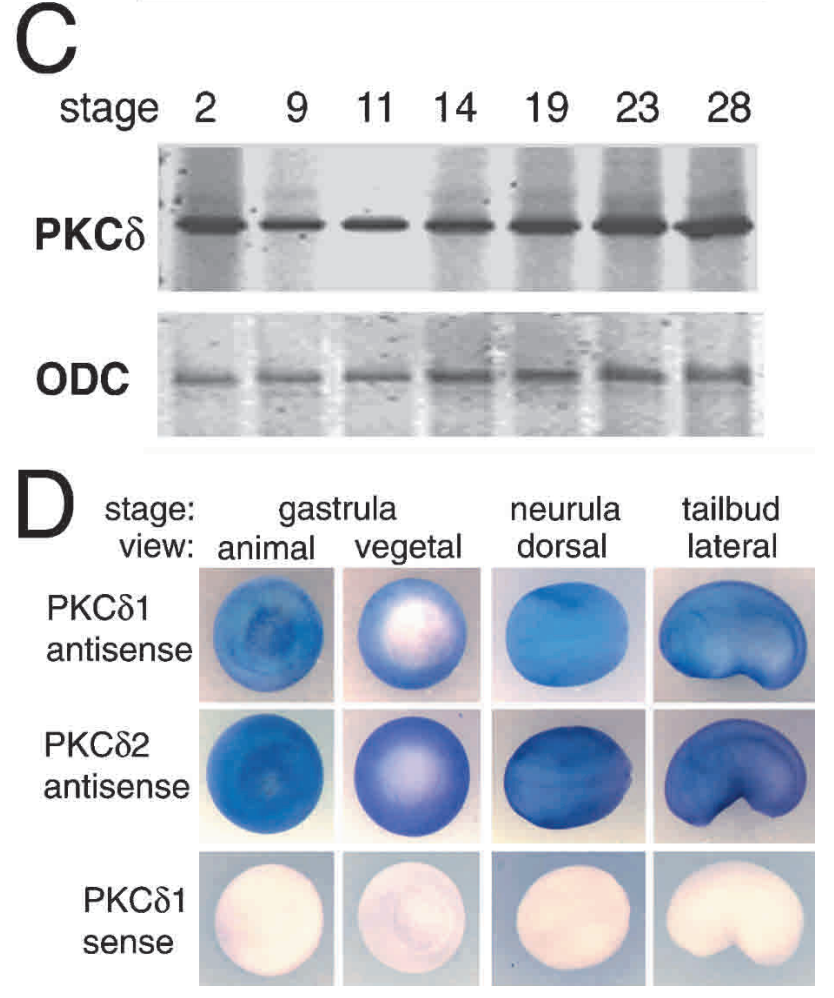

Figure 1. PKC $\delta$ is expressed during Xenopus embryogenesis. (A) Sequence alignment of Xenopus PKC $\delta 1$ and human PKC $\delta$. The DAG-binding C1 domain is underlined. The pseudosubstrate region is indicated by dots. (B) Sequence comparison between Xenopus PKC $\delta$ and some human PKC family members. Xenopus PKC $\delta 1$ is the most similar to human PKC $\delta$ in both the regulatory and the catalytic domains. (C) RT-PCR analysis of $P K C \delta$ expression during Xenopus development. Primers whose sequences were common between $P K C \delta 1$ and $P K C \delta 2$ were used. Stages are according to Nieukoop and Faber (1994). (D) In situ hybridization probing with $P K C \delta 1$ and $P K C \delta 2$ showing their ubiquitous expression.

expected to function as a dominant-negative form by binding to the catalytic domain of a native protein through its pseudosubstrate domain and/or by competitive binding to the activators. RNA encoding PKC $\delta \Delta \mathrm{C}$ was synthesized in vitro and injected into the two dorsal blastomeres of four-cell embryos. As shown in Figure $2 \mathrm{~A}, \mathrm{PKC} \delta \Delta \mathrm{C}$ severely inhibited gastrulation movements. Involution of the mesoderm was impaired, and the blastopore remained open or showed delayed closing. The same phenotype was observed in embryos injected with $P K C \delta 2$ lacking the catalytic domain (data not shown). The phenotype was rescued by full-length

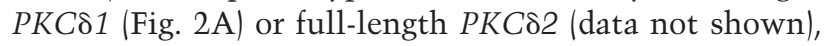
suggesting that $P K C \delta \triangle C$ functioned as a dominant-negative mutant of $P K C \delta$. It has been reported that a similar gastrulation-defect phenotype is caused by loss-of-function of the noncanonical Wnt signaling components, such as Xwnt11 (Tada and Smith 2000) and Xfz7 (Djiane et al. 2000).

To test whether PKC $\alpha$ or PKC $\beta$ has an activity similar to that of $\mathrm{PKC} \delta$, we constructed mutant genes encoding $\mathrm{PKC} \alpha$ and $\mathrm{PKC} \beta$ lacking the catalytic domain $(\mathrm{PKC} \alpha \Delta \mathrm{C}$ and $\mathrm{PKC} \beta \Delta \mathrm{C}$, respectively), expecting that they would function as dominant-negative mutants of their respective native forms. We injected the same amount of mRNA encoding PKC $\alpha \Delta \mathrm{C}$, PKC $\beta \Delta \mathrm{C}$, or $\mathrm{PKC} \delta \Delta \mathrm{C}$ into Xenopus embryos. Although comparable levels of the mutant proteins were detected by Western blotting, $\mathrm{PKC} \alpha \Delta \mathrm{C}$ and PKC $\beta \Delta \mathrm{C}$ did not have any effects on gastrulation, unlike PKC $\delta \Delta \mathrm{C}$ (data not shown). This result 
Kinoshita et al.

Figure 2. Overexpression of PKC $\delta$ lacking the catalytic domain inhibits gastrulation movements. (A) PKC $\delta 1$ lacking the catalytic domain (PKC $\delta \Delta \mathrm{C})$ inhibits gastrulation movements. RNA (100 pg) encoding PKC $\delta \Delta \mathrm{C}$ was injected into the two dorsal blastomeres of four-cell embryos. PKC $\delta \Delta$ C severely inhibited gastrulation movements, and this effect was rescued by the coinjection of $1 \mathrm{ng}$ of RNA encoding full-length PKC 1 . Embryos in the top panels are at the early neurula stage. $(B)$ In situ hybridization of early gastrula embryos probed with a pan-mesodermal marker, Xbra, and dorsal mesodermal markers chordin (chd) and goosecoid (gsc). (Left) Uninjected. (Middle) PKC $\Delta \mathrm{C}$ RNA (200 pg) was injected into all four blastomeres of four-cell embryos. (Right) In order to trace the cell lineage, mRNA encoding $\beta$-galactosidase ( $\beta$-gal) with a nuclear localization signal was coinjected with $P K C \delta \triangle C$ into two dorsal blastomeres of four-cell embryos. Cells expressing $\beta$-gal were stained in red. $(C)$ Immunostaining of the notochord and somites in $P K C \delta \Delta C$-injected embryos. $(D)$ The PKC $\Delta C$ mutant blocked the elongation of animal cap explants by activin. Activin RNA (0.5 pg) was injected with or without $100 \mathrm{pg}$ of $P K C \delta \triangle C$ RNA. (E) The induction of mesodermal markers by activin in animal caps was not affected by $\operatorname{PKC} \delta \Delta$ C. ui, uninjected; Em, whole embryo; gsc, goosecoid; chd, chordin.
A
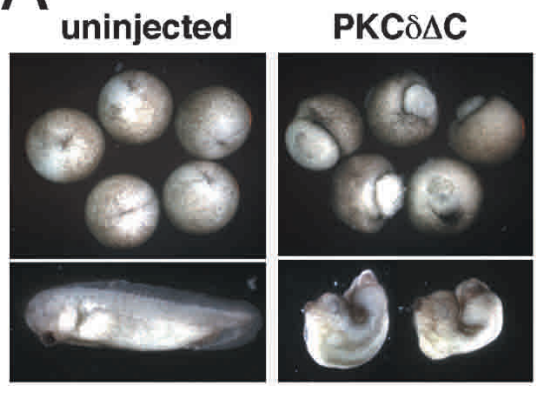

PKC $\delta$ C + PKC $\delta$
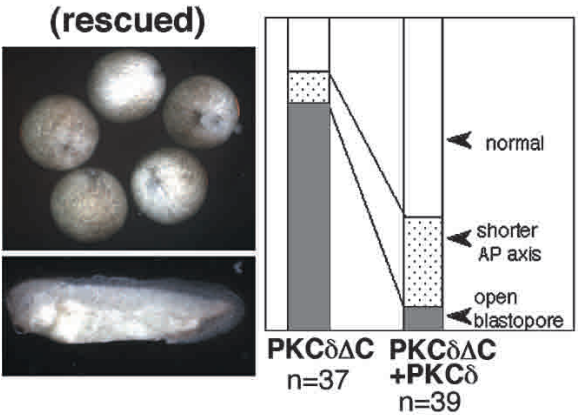

B

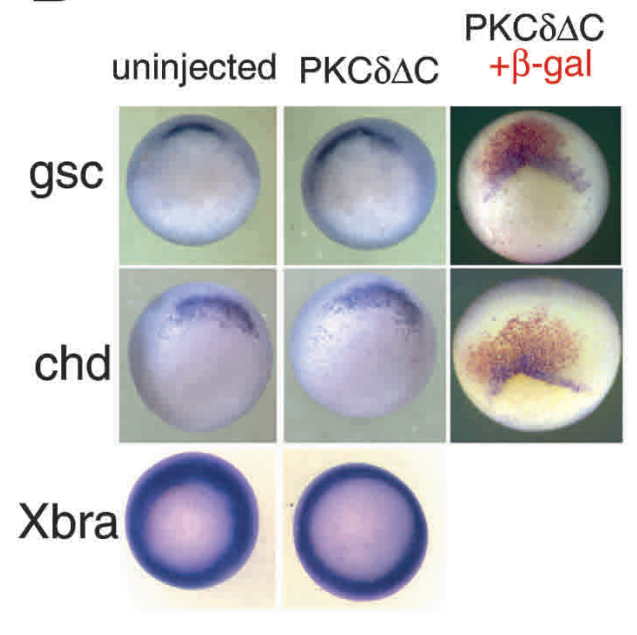

$D$
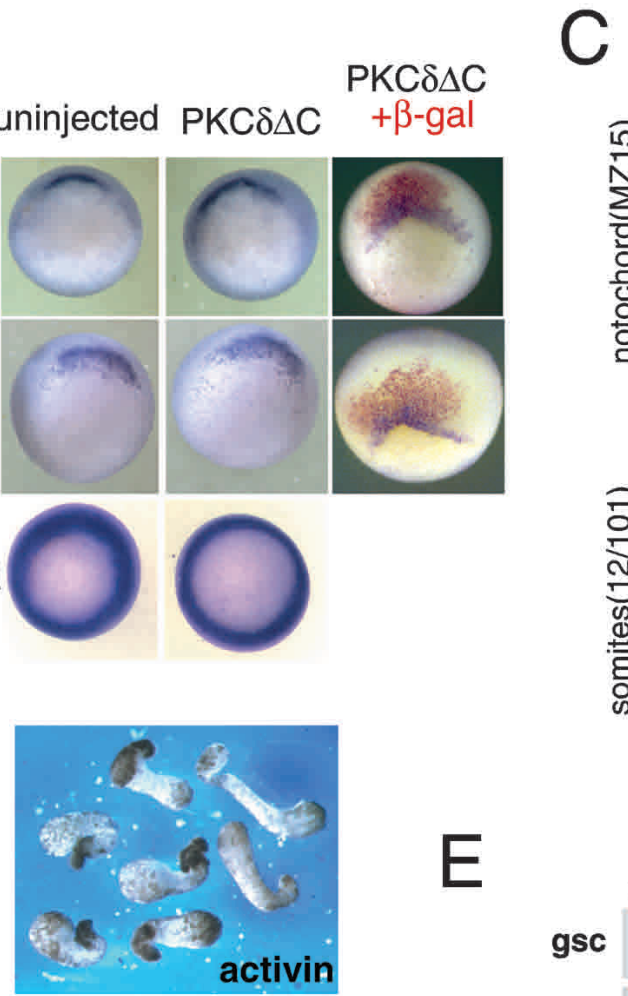

C $P K C \delta \Delta C$
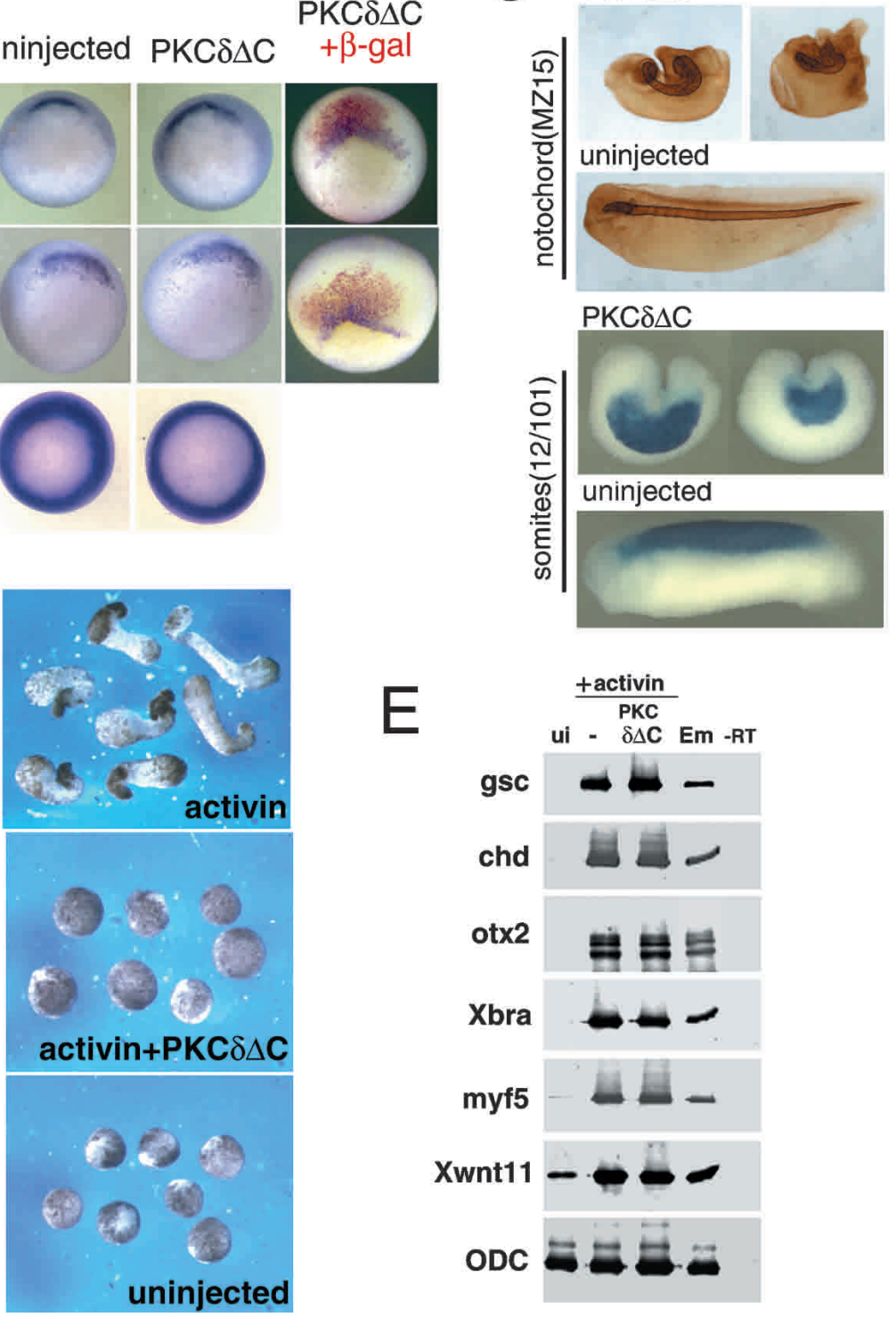

suggests that the role in gastrulation movements may be PKCס-specific.

To determine whether this gastrulation-defective phenotype was caused by a defect in mesodermal differentiation, the expression of mesodermal markers, we used in situ hybridization to examine a pan-mesodermal marker, Xbra, and dorsal mesodermal markers chordin (chd) and goosecoid (gsc). At the gastrula stage, PKC $\Delta \Delta C$ injected embryos expressed these markers at the same level as control embryos (Fig. 2B). In tadpoles, the noto- 
chord and somites were differentiated in the PKC $\Delta \mathrm{C}$ injected embryos, but the extension of these tissues was severely inhibited (Fig. 2C). These results indicated that the phenotype was caused not by a defect in mesoderm differentiation, but by a defect in morphogenetic movements.

We then tested whether $P K C \delta \Delta C$ inhibited the elongation of animal caps by activin. In this system, when the dorsal mesoderm is induced in animal cap explants by activin, the explants elongate by convergent extension movements. $P K C \delta \Delta C$ expression inhibited the elongation of explants by activin without affecting the induction of mesodermal markers (Fig. 2D,E). A similar effect has been observed as a result of inhibition of the noncanonical Wnt pathway. Our results suggest that PKC $\delta$ is also required for the convergent extension.
PKCs antisense morpholino also blocked gastrulation movements and convergent extension

To confirm that the effects of $P K C \delta \Delta C$ were due to the depletion of PKC $\delta$ activity, we made antisense morpholino oligonucleotides (MOs) for PKC $\delta$ and tested their effects on development. Because the highly homologous $P K C \delta 1$ and $P K C \delta 2$ are both expressed, MOs for both $P K C \delta 1$ and $P K C \delta 2$ were prepared. First, we confirmed that these MOs inhibited the translation of mRNA that has the corresponding sequences. As shown in Figure 3A, each MO blocked the production of its respective GFPtagged PKC $\delta$, but unrelated GFP was not affected.

To inhibit PKC\& synthesis in embryos, the MOs for $P K C \delta 1$ and $P K C \delta 2$ were mixed at an equimolar ratio and injected into four-cell embryos (the mixed MOs will be
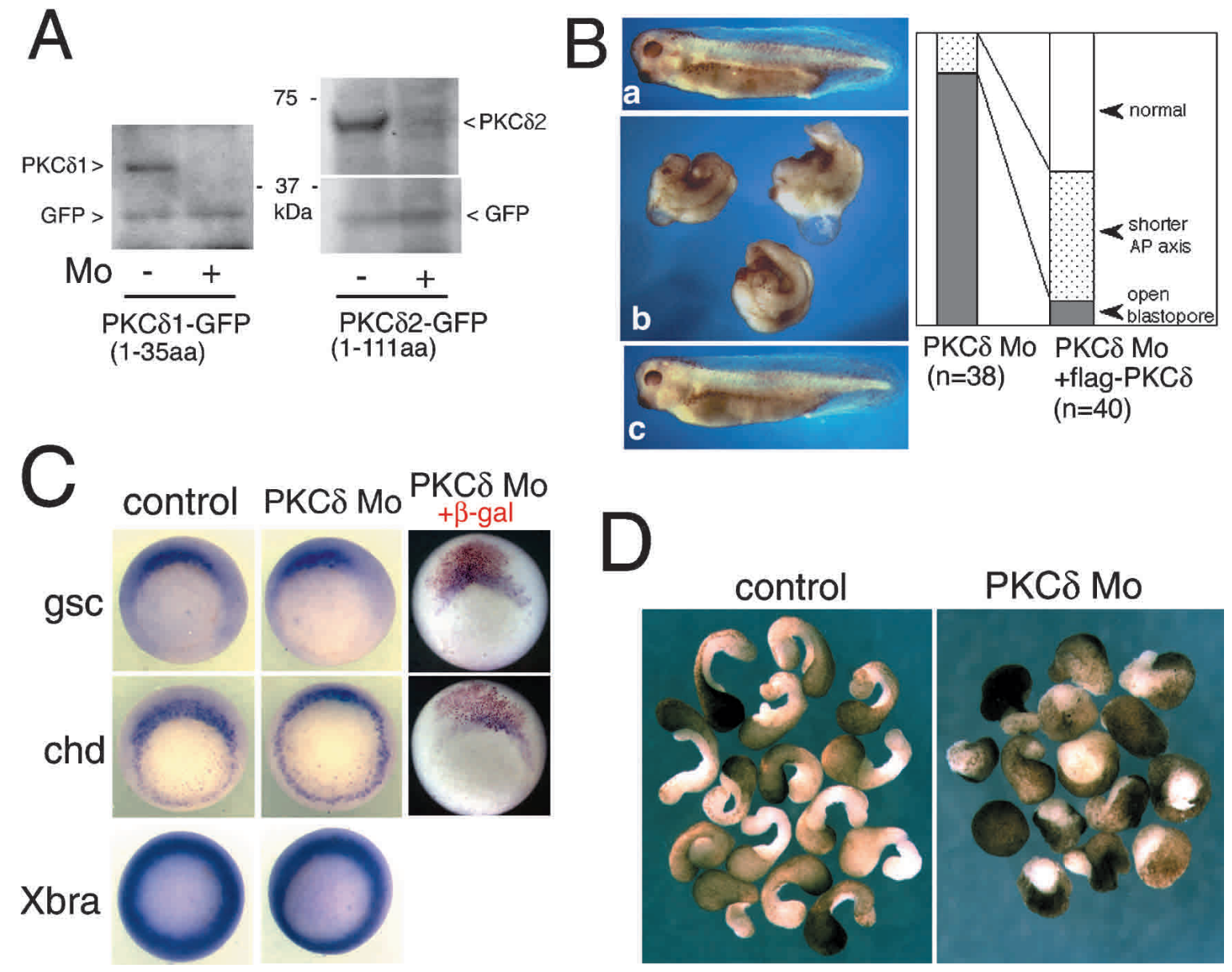

Figure 3. PKC $\delta$ antisense morpholino also blocked gastrulation movements. (A) Morpholino oligonucleotides (MOs) for PKC 1 and $P K C \delta 2$ inhibited the translation of mRNA that had the corresponding sequences. RNA encoding GFP-tagged PKC $\delta$ and unrelated GFP were coinjected with or without each MO. PKC 1 (left panel) and PKC $2 \mathrm{MO}$ (right panel) blocked the production of each GFP-tagged

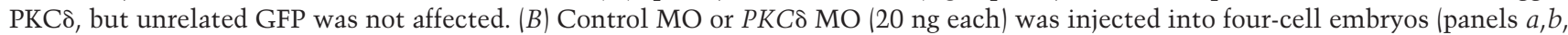
respectively). The PKC $\mathrm{MO}$ caused a gastrulation-defective phenotype that was indistinguishable from that of $P K C \delta \Delta C$-injected embryos. This phenotype was rescued by $1 \mathrm{ng}$ of full-length $P K C \delta 1$ RNA (panel $c) .(C)$ In situ hybridization of early gastrula embryos probed with chordin (chd), goosecoid (gsc), and Xbra. The left and middle panels show $20 \mathrm{ng}$ of control or PKC $\delta$ MO was injected into all four blastomeres of four-cell embryos. (Right) To trace the cell lineage, mRNA encoding $\beta$-gal with a nuclear localization signal was coinjected with $P K C \delta \mathrm{MO}$ into two dorsal blastomeres of four-cell embryos. (D) PKC $\mathrm{MO}$ inhibited the elongation of dorsal marginal zone explants. Twenty nanograms of MO were injected into the two dorsal blastomeres of four-cell embryos. 
referred to as $P K C \delta \mathrm{MO}$ hereafter). The $P K C \delta \mathrm{MO}$ caused a gastrulation-defective phenotype that was indistinguishable from that of PKC $\delta \triangle C$-injected embryos (Fig. 3B). This phenotype was efficiently rescued by Flagtagged PKC 1 , which do not have $5 '$-UTR binding to the MOs. In addition, MO-injected embryos expressed the mesodermal markers Xbra, chordin, and goosecoid, suggesting that the mesoderm differentiation was not affected (Fig. 3C). The similarity of the phenotypes of the embryos injected with $P K C \delta \Delta C$ and $P K C \delta \mathrm{MO}$ indicated that $\mathrm{PKC} \delta \Delta \mathrm{C}$ functioned as a dominant-negative mutant for PKC $\delta$. To investigate the role of PKC $\delta$ in convergent extension, we examined the effect of PKC $\mathrm{MOs}$ on the elongation of dorsal marginal zone (DMZ) explants. As shown in Figure 3D, the PKC $\mathrm{MO}$ inhibited the elongation of these explants, supporting the idea that PKC $\delta$ may be required for convergent extension.

PKC $\delta$ is translocated to the membrane in response to $X f z 7$ signaling and interacts with $X d s h$

The inhibition of convergent extension by the loss of PKC $\delta$ function strongly implies that PKC $\delta$ plays a role closely related to the noncanonical signaling pathway. It has been shown that Frizzled translocates Xdsh and PKC $\alpha$ from the cytoplasm to the plasma membrane in Xenopus embryos (Axelrod et al. 1998; Sheldahl et al. 1999; Medina and Steinbeisser 2000; Medina et al. 2000). To examine whether Frizzled also regulates the subcellular localization of $\mathrm{PKC} \delta$, Flag-tagged $P K C \delta$ and myctagged $X d s h$ were coexpressed with or without $X f z 7$ in animal cap explants of Xenopus embryos. The localization of the tagged proteins was then observed with a laser-scanning confocal microscope (Fig. 4A). In the absence of $X f_{z} 7 \mathrm{mRNA}, \mathrm{PKC} \delta$ and Xdsh were mainly in the cytoplasm. Interestingly, however, when $X f z 7$ was coexpressed, they were mostly localized to the plasma membrane. In general, this class of PKC binds to and is activated by DAG that is produced on the membrane upon extracellular signaling. Thus, DAG may be produced by $\mathrm{Xfz} 7$ and then localize PKC $\delta$ to the membrane, which further implies that PKC $\delta$ is involved in the Wnt/Xfz7 pathway.

The above finding that the cotranslocation of PKC $\delta$ and Xdsh from the cytoplasm to the membrane depended on $\mathrm{Xfz} 7$ function prompted us to examine whether these proteins might interact with each other. To test this possibility, Flag-tagged $P K C \delta$ and myc-tagged $X d s h$ were expressed in HEK293T cells and immunoprecipitation was performed. As shown in Figure 4B, PKC $\delta$ and Xdsh were coimmunoprecipitated. When the Flag and myc tags on $P K C \delta$ and $X d s h$ were exchanged, we obtained essentially the same result (data not shown). These findings indicated that PKC $\delta$ and Xdsh form a complex. To test whether the activation of $\mathrm{PKC} \delta$ by the phorbol ester PMA (phorbol 12-myristate 13-acetate) altered this binding property, we treated transfected HEK293T cells with PMA and performed an immunoprecipitation. PMA is known to be a potent activator for PKC $\delta$ and other

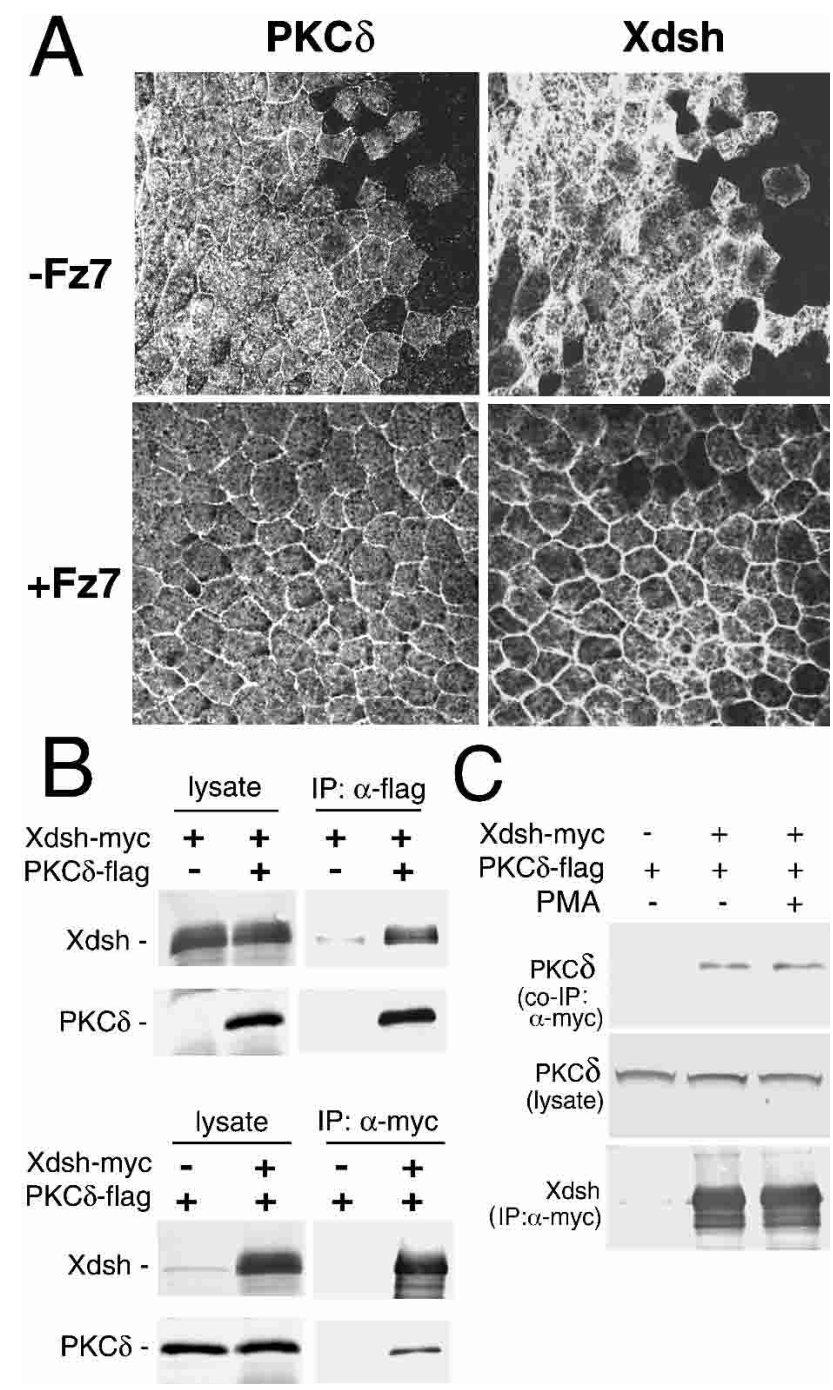

Figure 4. $\mathrm{PKC} \delta$ is localized to the plasma membrane with Xdsh by Xfz7 signaling. (A) Flag-tagged PKC $\delta$ RNA (200 pg) and myc-tagged $X d s h$ RNA (100 pg) were coinjected with or without $500 \mathrm{pg}$ of $X f_{z} 7$ RNA in the animal cap explants of Xenopus embryos. Their localization was observed by laser-scanning confocal microscopy. (B) Coimmunoprecipitation of PKC $\delta$ and Xdsh. Flag-tagged $P K C \delta$ and myc-tagged $X d s h$ were expressed as indicated in HEK293T cells. PKC $\delta$ and Xdsh coimmunoprecipitated, indicating that they form a complex. $(C)$ The indicated genes were expressed in HEK293T cells. PMA was added to the medium at a final concentration of $1 \mu \mathrm{M} 2 \mathrm{~h}$ before the cell lysate preparation. The addition of PMA did not change the amount of coimmunoprecipitated Xdsh and PKC $\delta$.

members of the novel and classical PKC subfamilies (Kikkawa et al. 1989; Bell and Burns 1991; Zhang et al. 1995). As shown in Figure 4C, PMA treatment did not change the amount of coimmunoprecipitated Xdsh and PKC $\delta$. In addition, a kinase-negative mutant of PKC $\delta$ was also coimmunoprecipitated with Xdsh in HEK293T lysates (data not shown), indicating that this physical interaction may not depend on the activity of PKC $\delta$. Taken together, these results suggest that $\mathrm{PKC} \delta$ and 
Xdsh form a complex, and this complex is translocated to the membrane upon activation of the $\mathrm{Xfz} 7$ signal.

\section{$P K C \delta$ is required for $X d s h$ activation by $X f z 7$ signaling}

The precise molecular mechanisms of the membrane localization of Xdsh by Wnt/Xfz7 signaling are not known. To investigate this issue, we next tested whether PKC $\delta$ is required for the Xfz7-dependent membrane localization of Xdsh. PKC $\mathrm{MO}$ was coinjected with myc-tagged $X d s h$ and $X f_{z} 7 \mathrm{mRNAs}$, and localization of Xdsh to the animal cap cells was observed. As shown in Figure 5A, the coinjection of $P K C \delta$ MO blocked the membrane localization of Xdsh in response to Xfz7.

$\mathrm{Xdsh}$ is a phosphoprotein whose phosphorylated state is elevated (hyperphosphorylated) upon the activation of the noncanonical Wnt signaling pathway (Yanagawa et al. 1995; Willert et al. 1997; Rothbacher et al. 2000; Tada and Smith 2000). This increase in phosphorylation can be monitored by a mobility shift of the Xdsh protein in SDS polyacrylamide gel electrophoresis (SDS-PAGE). To test whether PKC $\delta$ affects the phosphorylation state of $\mathrm{Xdsh}$, myc-tagged $X d s h$ mRNA was coinjected with

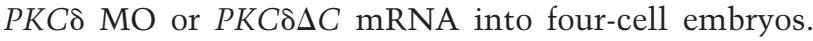
Animal cap explants were isolated at around stage 10, and their extracts were subjected to SDS-PAGE (Fig. 5B). The myc-tagged Xdsh protein was detected by Western blotting using an anti-myc antibody. Two bands were detected in the $X d s h$-injected samples. In the absence of $X f z 7$, the lower band was more intense than the upper band. When $X f z 7$ was coinjected, the upper band became much more intense. This indicated that Xdsh was hyperphosphorylated by $\mathrm{Xfz} 7$ signaling. The coinjection of $P K C \delta \triangle C$ or PKC $\mathrm{MO}$ blocked this hyperphosphoryla-
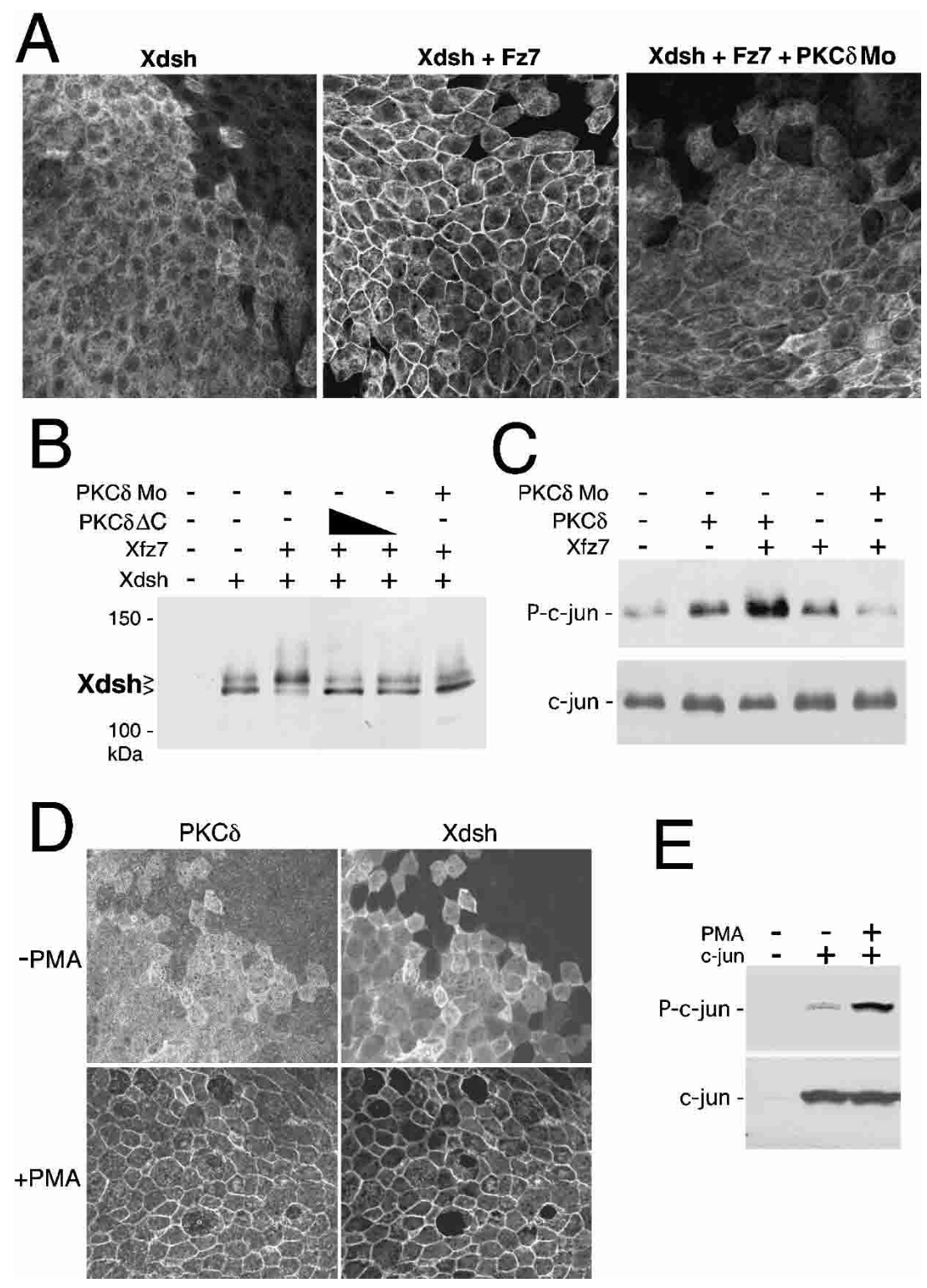

Figure 5. $\mathrm{PKC} \delta$ is required for the activation of Xdsh by Xfz7 signaling. (A) Twenty nanograms of $P K C \delta \mathrm{MO}$ were coinjected with 100 pg of myc-tagged $X d s h$ and 500 pg of $X f_{z} 7$ mRNAs, and the localization of Xdsh in animal cap explants was observed. The coinjection of $P K C \delta$ MO blocked the membrane localization of Xdsh by Xfz7. (B) Myc-tagged $X d s h$ and $X f_{z} 7 \mathrm{mRNAs}$ were coinjected with $P K C \delta$ MO or PKC $\triangle C$ mRNA. Animal cap explants were isolated at stage 10, and their extracts were fractionated by SDS-PAGE. Myc-tagged Xdsh protein was detected by Western blotting using an anti-myc antibody. Two bands were detected in all four lanes for $X d s h$-injected samples. (C) PKC $\delta$ is required for JNK activation by Xfz7. GAL4 DNA-binding domain (DBD)-tagged c-Jun mRNA was injected, and the phosphorylation levels of cJun were detected by Western blotting using anti-phosphorylated c-Jun (P-c-Jun) and antiDBD antibodies (c-Jun). (D) Animal cap explants expressing myc-tagged $X d s h$ and Flagtagged $P K C \delta$ were treated with PMA, and the localization of Xdsh and PKC $\delta$ was observed. Xdsh was translocated to the plasma membrane by PMA. (E) PMA can activate JNK in animal cap explants. Isolated explants were treated with or without $1 \mu \mathrm{M}$ PMA for $1 \mathrm{~h}$. The JNK activity was detected by an antiphospho-c-Jun antibody. 
tion of Xdsh. These results indicated that PKC $\delta$ is required for both the membrane localization and the phosphorylation of Xdsh, suggesting that PKC $\delta$ is essential for the signaling from $\mathrm{Xfz} 7$ to $\mathrm{Xdsh}$.

If the Xdsh function requires PKC $\delta$ activity, the activation of JNK in the noncanonical Wnt pathway should be blocked by the loss of PKC $\delta$ function. To examine this possibility, we assayed the JNK activity. GAL4 DNAbinding domain (DBD)-tagged c-Jun mRNA was injected into Xenopus embryos, and the phosphorylation level of c-Jun was assessed by Western blotting using anti-phosphorylated-c-Jun and anti-DBD antibodies. As shown in Figure $5 \mathrm{C}$, the overexpression of $\mathrm{PKC} \delta$ or $\mathrm{Xfz} 7$ alone slightly activated the JNK activity. However, the activity was greatly enhanced by the coexpression of $X f z 7$ and $P K C \delta$. Moreover, PKC $\delta$ MO blocked the activation of JNK by Xfz7. These results indicated that PKC $\delta$ is required for the activation of JNK by Xfz7 signaling.

\section{Activation of PKC $\delta$ is sufficient for Xdsh translocation} and for activation of the INK pathway

As described above, PKC $\delta$ and Xdsh form a complex, and both are translocated to the plasma membrane upon the activation of the noncanonical Wnt pathway. We postulated that $\mathrm{PKC} \delta$ recruits Xdsh to the membrane in this process. If this is true, the activation of PKC $\delta$ might be sufficient for the translocation of Xdsh. To test this possibility, we injected RNAs encoding Flag-tagged PKC 1 and myc-tagged Xdsh into Xenopus embryos, and the animal caps were explanted and treated with PMA. PMA is a functional analog of DAG that activates PKC on the membrane by binding to the $\mathrm{C} 1$ domain. As shown in Figure 5D, both PKC $\delta$ and Xdsh were translocated to the plasma membrane by PMA within 15 min. In addition, PMA treatment activated the JNK in the animal cap explants (Fig. 5E). Thus, PKC $\delta$ activation is sufficient for Xdsh translocation and the activation of downstream signaling.

The PKC loss-of-function phenotype is partially rescued by the overexpression of active MKK7

We have shown that $\mathrm{PKC} \delta$ is required for the activation of JNK by Xfz7. If the gastrulation-defective phenotype caused by $P K C \delta \mathrm{MO}$ is due to the blockade of JNK activation, it might be rescued by the overexpression of $M K K 7$, which is known to activate JNK directly. To examine this possibility, we coinjected $P K C \delta$ Mo with constitutively active (CA) MKK7 (Yamanaka et al. 2002). Closure of the blastopore of the injected embryos was compared at stage 14, which is when the blastopore in the control embryos was completely closed. PKC $\mathrm{MO}$ blocked the gastrulation movement in more than $90 \%$ of the injected embryos (Fig. 6A). PKC mRNAs rescued the phenotype completely and partially, respectively, suggesting that $\mathrm{MKK} 7 / \mathrm{JNK}$ functions at least in part downstream of PKC $\delta$. This result supported the idea that Xfz7 regulates JNK activity through PKC $\delta$. At the tadpole stage, the embryos rescued by $M K K 7$ showed short trunks and defects in head formation (Fig. 6B). This partial rescue suggests that PKC $\delta$ may act not only through the JNK pathway, but in other pathways as well.

\section{PKCS is not essential for the canonical Wnt pathway}

We next tested whether PKC $\delta$ plays a role in the canonical Wnt pathway. It is known that the ectopic expression

Figure 6. PKC $\delta$ loss-of-function is rescued by overexpression of active MKK7. (A) Twenty nanograms of $P K C \delta \mathrm{MO}$ were coinjected with $1 \mathrm{ng}$ of $P K C \delta 1$, and $200 \mathrm{pg}$ of constitutively active (CA) MKK7. The closure of the blastopore of injected embryos was compared at stage 14 , when the blastopore in the control embryos was completely closed. PKC $\mathrm{MO}$ blocked gastrulation movement. PKC $\delta$ mRNA rescued the phenotype completely, and CA MKK7 mRNA partially rescued it. $(B)$ At the tadpole stage, embryos coinjected with CA $M K K 7$ showed a partially rescued phenotype. $(C)$ To test whether PKC $\delta$ is essential for the canonical Wnt pathway, $100 \mathrm{pg}$ of $P K C \delta \Delta C$ or $20 \mathrm{ng}$ of

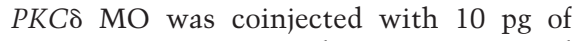
$X w n t 8$ into Xenopus embryos. $P K C \delta \Delta C$ and $P K C \delta$ MO did not inhibit the induction of siamois or Xnr3, indicating that PKC $\delta$ does not affect the canonical Wnt signaling pathway.

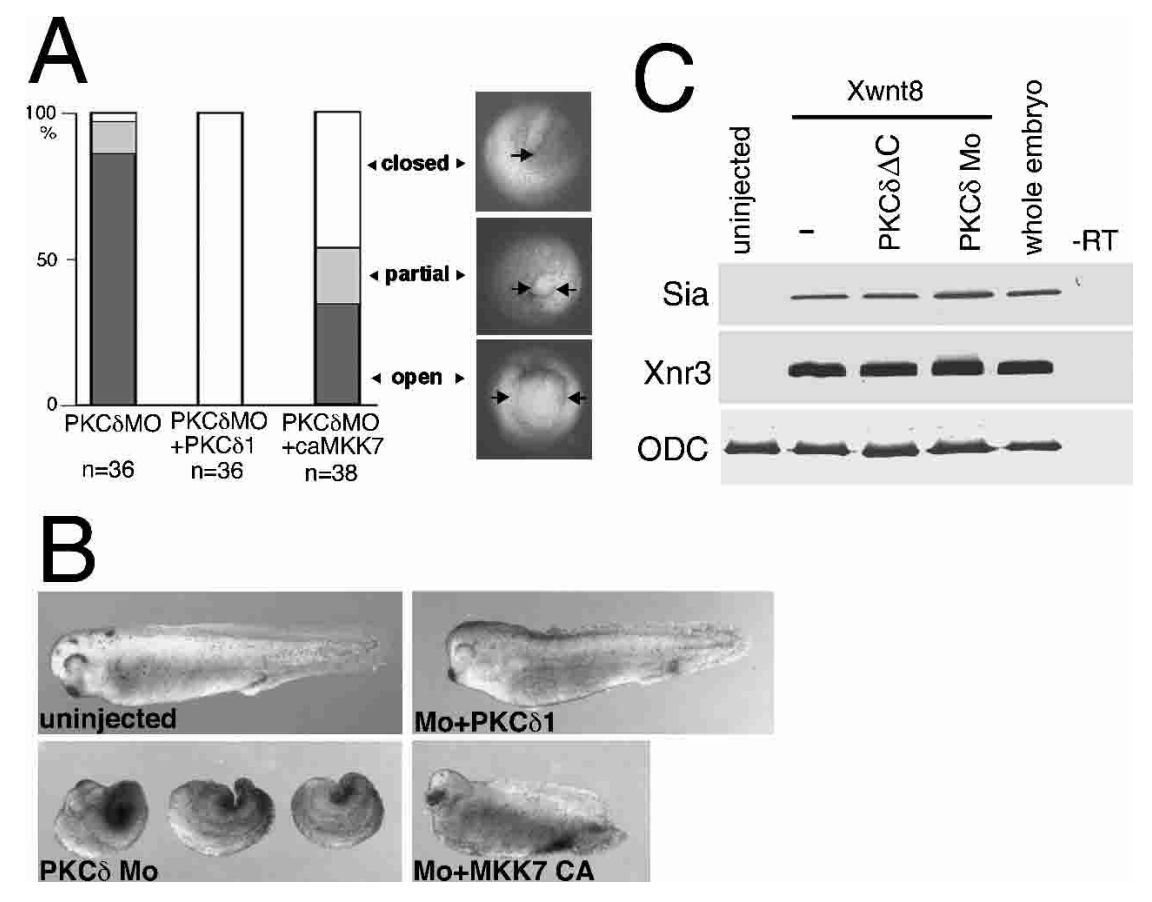


of Xwnt8 induces secondary axis formation (Smith and Harland 1991) and marker genes such as siamois and $X n r 3$ by activating the canonical Wnt pathway in Xenopus embryos (Brannon and Kimelman 1996; Carnac et al. 1996; McKendry et al. 1997). When Xwnt8 was coinjected with $P K C \delta \Delta C$ or PKC $\mathrm{MO}$, the induction of siamois and Xnr3 by Xwnt8 was not inhibited (Fig. 6C). Furthermore, the secondary axis formation by Xwnt8 was not inhibited by the loss of PKC $\delta$ function (data not shown). Therefore, although $\mathrm{PKC} \delta$ is required for the Wnt/JNK pathway, it may not be necessary for the canonical Wnt pathway, which is independent of the membrane relocalization of Dishevelled (Yang-Snyder et al. 1996; Axelrod et al. 1998; Moriguchi et al. 1999; Rothbacher et al. 2000).

PKCS regulates the cell shape and intercalative behavior of the mesodermal cells during convergent extension movements

During convergent extension of the mesoderm, cells are polarized and aligned mediolaterally, then intercalated. To test whether PKC $\delta$ is required in this process, the convergent extension in DMZ explants was observed microscopically. The procedure was basically according to Wallingford et al. (2000). PKCઈ MO, Rhodamine dextran, and mRNA for Venus (a YFP variant; Nagai et al. 2002) fused with the membrane localization signal of K-ras (mb-Venus) were coinjected into one of the two dorsal blastomeres at the four-cell stage. As a control, mb-Venus mRNA alone was injected into the other dorsal blastomere (Fig. 7A). At the gastrula stage, dorsal marginal zone explants were cultured on a cover glass coated with fibronectin. These explants adhered to the surface, and subsequently, convergent extension movements occurred in the mesoderm. In the absence of $P K C \delta \mathrm{MO}$, red cells and non-red cells intercalated (Fig. 7B). In the $P K C \delta$ MO-injected explants, the non-red cells, which were assumed to lack the MO, were polarized and showed convergent extension movements. In contrast, the red cells (MO-injected cells) were round-shaped, were not polarized, and did not participate in the intercalation, even when they were adjacent to the intercalating cells. Thus, this inhibition by PKC $\delta$ MOs appeared to be cell-autonomous. These results indicated that PKC $\delta$ is essential for the cell polarization during convergent extension movements.

To investigate the subcellular localization of PKC $\delta$ and Xdsh in the dorsal mesodermal cells, we expressed these proteins tagged with Venus. Interestingly, these were accumulated around the tips of the elongated cells (Fig. 7C). However, Xdsh lacking the DEP domain, which is known to play an important role in the tissue polarity (Axelrod et al. 1998) was almost uniformly distributed (Xdsh $\triangle \mathrm{DEP})$. In addition, Rac tagged with Venus is also localized in the same region. The finding that Rac forms a complex with Xdsh (Habas et al. 2003) suggests that Rac may be recruited by $\mathrm{Xdsh}$.

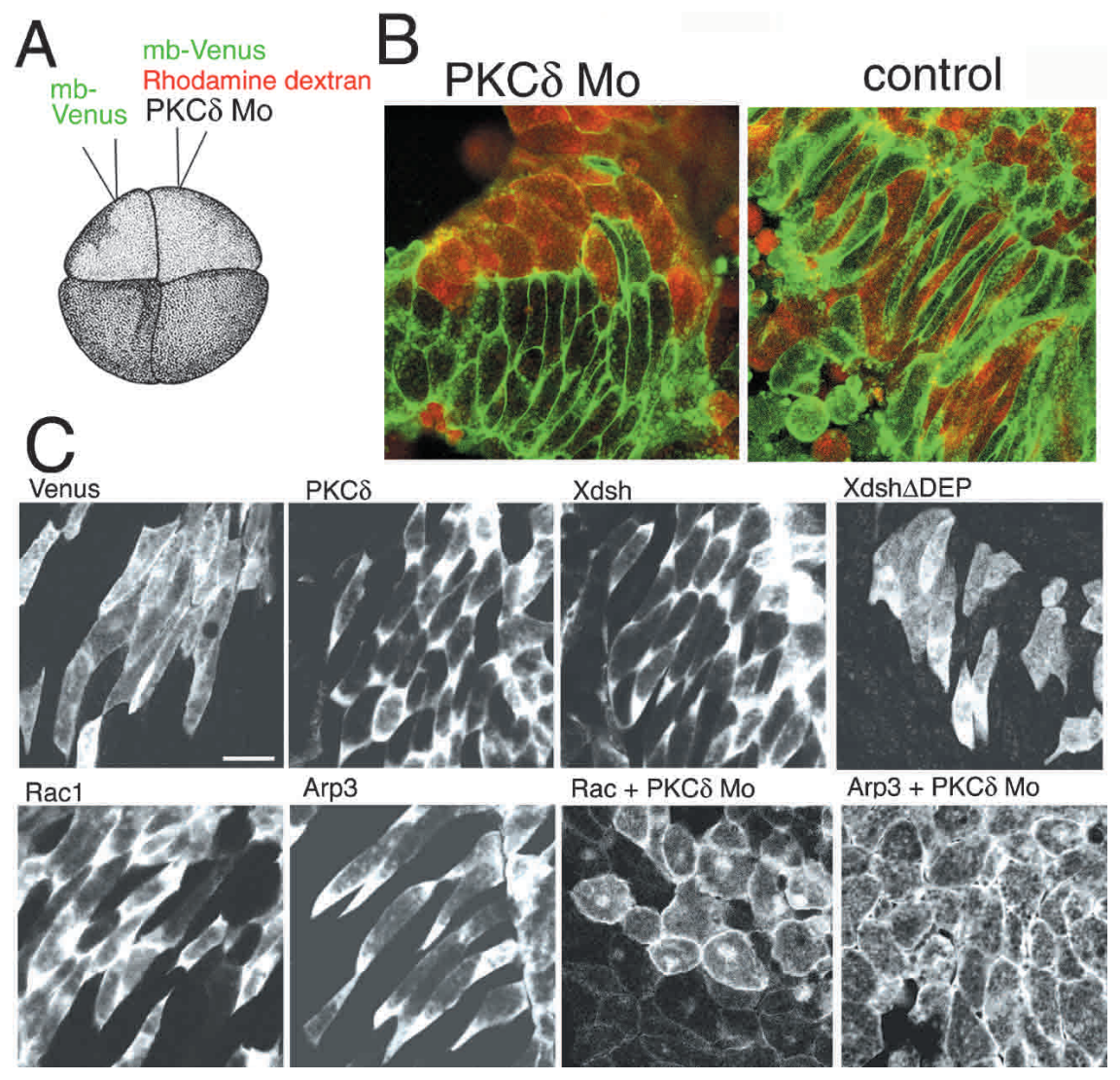

Figure 7. PKC $\delta$ is required for convergent extension movements. (A) PKC $\delta \mathrm{MO}$, Rhodamine dextran, and mRNA for Venus fused with a membrane localization signal (mb-Venus) were coinjected into one of the two dorsal blastomeres at the four-cell stage. As a control, mb-Venus mRNA alone was injected into the other dorsal blastomere of the same embryo. (B) At the gastrula stage, dorsal marginal zone (DMZ) explants were cut and cultured on a cover glass coated with fibronectin, and the convergent extension movements were observed by laser-scanning confocal microscopy. $(C)$ The indicated cDNAs were fused to Venus and expressed in the dorsal mesodermal cells. DMZ explants were cultured and observed as described above. Bar, $50 \mu \mathrm{m}$. 
The process of convergent extension movements includes cell shape change and cell movements, suggesting that the regulation of actin polymerization may be crucial for the process. It is known that the Arp $2 / 3$ complex is a key component of the assembly of actin filaments and the cell motility (Suetsugu et al. 2002; Weaver et al. 2003). Thus, we tested the localization of the Arp3 tagged with Venus in these cells. As shown in Figure 7C, Arp3 is also localized around the tips of these cells. In addition, Rac and Arp3 were localized almost uniformly on the membrane or the cortical region when PKC $\delta \mathrm{MO}$ was injected. The Arp2/3 complex may be recruited by PKC $\delta$ and its downstream PCP signaling and may regulate the cell polarity, bipolar protrusive activity, and cell motility in these cells.

\section{Discussion}

PKCS is essential for Xdsh function

in the noncanonical Wnt pathway

The membrane localization of Xdsh is thought to be an important step for Xdsh activation in the noncanonical Wnt pathway (Moriguchi et al. 1999; Rothbacher et al. 2000; Wallingford et al. 2000; Axelrod 2001). However, the molecular mechanism of this process has not been well understood. In the present study, we identified $\mathrm{PKC} \delta$ in the Xenopus embryo and investigated its role in the Wnt/JNK pathway. These analyses revealed that PKC $\delta$ is essential for the translocation and activation of Xdsh in the Wnt/JNK pathway, based on the following findings: (1) PKC $\delta$ was translocated from the cytoplasm to the plasma membrane in response to $\mathrm{Xfz} 7$ signaling. (2) The loss of PKC $\delta$ function inhibited the membrane localization and hyperphosphorylation of Xdsh. (3) PKC $\delta$ was also essential for JNK activation by Xfz7. (4) PKC $\delta$ physically interacted with Xdsh. (5) The activation of PKC $\delta$ by PMA was sufficient for the translocation of $\mathrm{Xdsh}$ and the activation of the JNK pathway. Taking all these results together, we propose the following model of the Xdsh activation mechanism in the noncanonical Wnt/JNK pathway. In the absence of Wnt/Xfz7 signaling, $\mathrm{Xdsh}$ and PKC $\delta$ localize to the cytoplasm. It is likely that $\mathrm{Xdsh}$ and $\mathrm{PKC} \delta$ form a complex even in the absence of $\mathrm{Xfz} 7$ signaling. This was suggested by our finding that the Xdsh-PKC $\delta$ complex formation was not dependent on Frizzled signaling or PKC $\delta$ activity. However, further investigations may be necessary to confirm this hypothesis. When the receptor is activated, the phosphatidylinositol pathway may be activated and produce the PKC activator, diacylglycerol (DAG). Then, $\mathrm{PKC} \delta$, which has a DAG-binding $\mathrm{C} 1$ domain, is translocated and recruits $\mathrm{Xdsh}$ to the membrane. PKC $\delta$ may be activated by DAG, resulting in the hyperphosphorylation of Xdsh. The membrane localization and/or phosphorylation of Xdsh activate the downstream JNK pathway.

\section{How does Frizzled activate PKC\&?}

Xenopus PKC $\delta$ has a highly conserved C1 domain, which binds to DAG and phorbol esters such as PMA, a func- tional analog of DAG. PKC $\delta$ was translocated to the plasma membrane in animal cap cells in response to both $\mathrm{Xfz} 7$ and PMA. These results and other observations suggested that $\mathrm{Xfz} 7$ might activate PKC $\delta$ through DAG on the plasma membrane, although there is no direct evidence that activation of the Wnt/Frizzled pathway produces DAG. However, heterotrimeric G proteins have been implicated in the Wnt/Frizzled pathway (Liu et al. 1999, 2001). It has been shown that certain heterotrimeric $G$ proteins coupled with seven-transmembrane receptors activate phospholipase C- $\beta$, which hydrolyzes phosphatidylinositol phosphate to produce DAG and inositol triphosphate. In addition, Xfz7 function is blocked by pertussis toxin, which inhibits the Gi family (Sheldahl et al. 1999; Winkbauer et al. 2001). Taken together, these findings suggest that Xfz7 probably activates $\mathrm{PKC} \delta$ through a heterotrimeric $\mathrm{G}$ protein that produces DAG. It will be important to determine which $G$ protein is involved in this pathway and whether DAG is produced by $\mathrm{G}$ protein function.

\section{Mechanism of activation of the Xdsh/JNK pathway}

In this study, we showed that Xdsh and PKC $\delta$ form a complex and that the complex formation is not dependent on PKC $\delta$ activity. In addition, the activation of PKC $\delta$ is sufficient and necessary for the membrane localization of $\mathrm{Xdsh}$ in response to $\mathrm{Xfz} 7$. These findings suggest that $\mathrm{Xfz} 7$ may be involved in the translocation of the PKC $\delta$-Xdsh complex to the plasma membrane through the production of DAG. In other words, PKC $\delta$ recruits $\mathrm{Xdsh}$ to the membrane in response to $\mathrm{Xfz} 7 \mathrm{sig}$ naling. It will be necessary to determine which domain of Xdsh interacts with PKC $\delta$ and vice versa. Our preliminary work showed that a C-terminal fragment including the DEP domain of Xdsh coimmunoprecipitated with PKC $\delta$ as well as the full-length Xdsh protein (A. Miyakoshi, unpubl.). This is consistent with the fact that this domain of Dishevelled is sufficient for its membrane translocation and function in the PCP pathway (Axelrod et al. 1998; Boutros et al. 1998; Moriguchi et al. 1999; Rothbacher et al. 2000; Wallingford et al. 2000).

The Dishevelled protein is known to be hyperphosphorylated in response to Wnt and Frizzled (Yanagawa et al. 1995; Willert et al. 1997; Rothbacher et al. 2000; Tada and Smith 2000). We showed that the loss of PKC $\delta$ function blocked this phosphorylation of Xdsh. It has been shown that the phosphorylation and membrane localization of Xdsh are closely related (Rothbacher et al. 2000). The simplest model is that DAG activates PKC $\delta$ on the membrane, and PKC $\delta$ phosphorylates Xdsh directly. Kuhl et al. (2001) showed that PKC $\alpha$ phosphorylates $\mathrm{Xdsh}$ in vitro. PKC $\delta$ may have the similar activity. However, Dishevelled is known to interact with other kinases, such as casein kinases 1 and 2, Par-1, and PAK1/ MuSK (Willert et al. 1997; Sun et al. 2001; Vielhaber and Virshup 2001; Luo et al. 2002). PKC $\delta$ may regulate such protein kinases and thus indirectly regulate Xdsh phosphorylation. It would be interesting to examine whether PKC $\delta$ phosphorylates Xdsh directly, and to elucidate the 
role of Xdsh phosphorylation in its localization and in the activation of downstream signaling. Determination of the sites in Xdsh that are phosphorylated by Xfz7 signaling awaits further study.

The following three results indicate that PKC $\delta$ mediates the activation of JNK by Xfz7: (1) JNK activation by $\mathrm{Xfz} 7$ was inhibited by the loss of PKC $\delta$ function. (2) The activation of PKC $\delta$ by PMA was sufficient for JNK activation. (3) The gastrulation-defective phenotype of $P K C \delta$ MO was rescued by active MKK7, which activates JNK. JNK has been implicated in the noncanonical Wnt pathway (Boutros et al. 1998; Yamanaka et al. 2002), but it is still unknown how Xdsh activates the JNK pathway. The membrane localization and/or phosphorylation of Xdsh may enable other proteins such as Rho to interact with Xdsh to activate the JNK cascade. It will be interesting and important to learn how JNK regulates convergent extension movements during gastrulation.

\section{Specificity of PKC in the Wnt pathway}

The PKC family is comprised of three subfamilies, cPKC, nPKC, and aPKC. cPKC and nPKC can be activated by DAG and/or $\mathrm{Ca}^{2+}$, both of which may increase upon activation of the Wnt signaling pathway. In addition to $\mathrm{PKC} \delta$, which belongs to the nPKC subfamily, two cPKCs, PKC $\alpha$ and PKC $\beta$, are expressed during Xenopus gastrulation. We decided to focus on PKC $\delta$ for the following reason. Truncated PKC $\alpha$, PKC $\beta$, and PKC $\delta$ lacking the catalytic domain were constructed and overexpressed in Xenopus embryos, with the assumption that they would function as dominant-negative mutants. PKC $\delta \Delta \mathrm{C}$ seemed to function as a dominant-negative mutant because the phenotype of Xenopus embryos injected with $P K C \delta \Delta C$ was very similar to that caused by the injection of $P K C \delta \mathrm{MO}$ and was rescued by full-length PKC $\delta$. Of these three mutants, PKC $\delta \Delta \mathrm{C}$ blocked gastrulation movements very effectively, whereas PKC $\alpha \Delta \mathrm{C}$ or $\mathrm{PKC} \beta \Delta \mathrm{C}$ had little effect, although comparable levels of protein expression were detected by Western blotting. We also made constructs with point mutations at the lysine residue in the ATP-binding domain, which are generally used as dominant-negative mutants for PKCs and other kinases (e.g., see Li et al. 1996). When these forms were overexpressed, the PKC $\alpha$ and PKC $\beta$ mutants had no effect on gastrulation (data not shown). These results indicated that PKC $\alpha$ and PKC $\beta$ might not play a crucial role in this process. Although PKC $\delta$ regulates the Wnt/JNK pathway, as we have shown, it is possible that PKC $\alpha$ and/or PKC $\beta$ may mainly be involved in the Wnt/ $\mathrm{Ca}^{2+}$ pathway, although we cannot completely exclude the possibility that PKC $\alpha$ and/or PKC $\beta$ may also be involved in the Wnt/JNK pathway.

\section{Role of PKC $\delta$ in gastrulation movements}

Convergent extension is comprised of several steps involving changes in cell morphology and movements. As convergent extension begins, cells extend lamellipodia in random directions. The cells are then polarized and become narrow along the mediolateral direction, followed by the intercalation of these cells. Xdsh function is required for this regulation of cell polarity (Wallingford et al. 2000). We clearly showed that PKC $\mathrm{MO}$-injected cells were not polarized, nor did they participate in the intercalation, indicating that PKC $\delta$ is essential for controlling cell polarity and the change in cell shape during convergent extension movements.

Interestingly, PKC $\delta$ and Xdsh tagged with Venus were localized around the tips of the elongated cells. In addition, Rac and Arp3 are also localized in the same regions. It is known that these regions have a lamellipodial protrusive activity. Arp3 is one of Arp2/3 complex components, which is a key regulator of the actin polymerization in lamellipodial protrusion of membranes (Suetsugu et al. 2002; Weaver et al. 2003). The Arp2/3 complex is also known to be regulated by Rac (Suetsugu et al. 2002). It is strongly suggested that the proper localization of Rac, Arp3, and other cytoskeletal regulators may be important for cell elongation and intercalative movements. Without PKC $\delta$ function, cells were round-shaped, and Rac and Arp3 did not localize in the specific region. This suggests that $\mathrm{PKC} \delta$, Xdsh and the downstream PCP signaling may be required for the localization of such machinery, including the Arp2/3 complex.

\section{Materials and methods}

Plasmids, RNA synthesis, and morpholino oligos

Our Xenopus EST database (NIBB XDB, http://Xenopus.nibb. ac.jp) was searched with the cDNA sequences of mammalian nPKC family members using BLAST. Full-length cDNA clones, XL011f02 and XL066d07, were identified. These clones were sequenced and designated $\mathrm{PKC} \delta 1$ and $\mathrm{PKC} \delta 2$, respectively. GenBank accession numbers are AB109739 and AB109740, respectively. Plasmids for the expression in Xenopus embryos were constructed with PCR products inserted into the expression vector pCS2+. Capped mRNAs were synthesized using the mMESSAGE mMACHINE kit (Ambion).

PKC $\delta \Delta \mathrm{C}$ contained the $\mathrm{N}$-terminal regulatory domain (1-347 amino acids) of PKC $\delta 1$. A plasmid bearing the gene for constitutively active MKK7 (MKK7 DED) was a kind gift from Dr. E. Nishida (Kyoto University, Japan). The plasmid bearing the gene for GAL4(DBD)-tagged c-Jun was a kind gift from Dr. M. Tada (National Institute for Medical Research, UK). The myc-Xdsh was a kind gift from Dr. R. Harland (University of California, Berkeley). For the Venus-tagged constructs, the indicated fragments were amplified with PCR, fused to Venus gene (Nagai et al. 2002), and sequenced. For mb-Venus, a cDNA fragment of the C-terminal region (158-188 amino acids) of Xenopus K-ras (Baum and Bebernitz 1990) was cloned by PCR using the plasmid XL213p09 (NIBB XDB) as a template. Xdsh $\triangle$ DEP contained the $\mathrm{N}$-terminal region (1-426 amino acids). Xenopus Rac (GenBank accession no. AF174644) was cloned by PCR using neurula cDNA. Arp3 was cloned by PCR using the plasmid XL019o05 (NIBB XDB). PKC $\delta$ and Arp3 were fused to the N terminus of Venus, and $\mathrm{Xdsh}$ and $\mathrm{Xdsh} \triangle \mathrm{DEP}$ were fused to the C terminus.

Antisense morpholinos were obtained from Gene Tools. The morpholino oligo sequences were as follows: PKC $\delta 1 \mathrm{MO}, 5^{\prime}$ AGGATATGCGTAGGAAGGAGACATG-3'; PKCס2 MO, 5'- 
AGGATAAGCGTAGGAAAGGAGCCAT-3'; Control MO, 5' CCTCTTACCTCAGTTACAATTTATA-3'.

\section{In situ hybridization and RT-PCR analysis}

In situ hybridization in Xenopus was carried out as described in Harland (1991). The detection of $\beta$-galactosidase activity for tracing cell lineage was carried out as described by Kurata and Ueno (2003). For RT-PCR analyses, RNA from Xenopus embryos was prepared with Trizol (Life Technologies). cDNA was synthesized with Reverse Transcriptase (\#TRT-101, Toyobo). Sequences of the primers for Xbra, Xnr3, and Xotx2 were as described in Yamamoto et al. (2001) and those for chordin, goosecoid, siamois, and ODC were as described in Dr. De Robertis' home page (http://www.hhmi.ucla.edu/derobertis/ index.html). Primers for Xmyf5 were 5'-CAGAATGGA GATGG TAGATAGC-3' and 5'-AGCCTGGTTCACTTTCTT TAGC-3'; those for Xwnt11 were 5'-AAGT-GCCACGGAGT GTCT GG-3' and 5'-CTCAGACTCTCTCACTGGCC-3'; and those for $P K C \delta$ were $5^{\prime}$-TTTATTAACCCCAAGATGGAGCG$3^{\prime}$ and $5^{\prime}$-AACTACATTCAAGTAACCAG-3'.

\section{Whole-mount immunostaining and immunocytochemistry} of Xenopus embryos

The procedure for whole-mount immunostaining was as described in Kurata et al. (2001). The antibodies were MZ15 for notochord (a kind gift from Dr. F. Watt; Smith and Watt 1985) and 12/101 for somites (Development Studies Hybridoma Bank; Kintner and Brockes 1984). As secondary antibodies, horseradish peroxidase-conjugated and alkaline phosphatase-conjugated antibodies were used for MZ15 and 12/101, respectively.

For immunocytochemistry, each epitope-tagged mRNA was injected into the animal pole of two-cell embryos. The animal caps were dissected from stage 9-10 embryos and fixed with MEMFA, followed by immunostaining by a standard method using a fluorescence-labeled secondary antibody. The localizations were determined by laser-scanning confocal microscopy, using a Carl Zeiss LSM510 microscope. The antibodies for immunocytochemistry were anti-myc 9E1 (Boehringer Mannheim) and rabbit polyclonal anti-Flag (Sigma) antibodies. For PMA treatment, phorbol 12-myristate 13-acetate (\#P1585, Sigma) was used.

\section{Elongation assay in Xenopus animal cap and DMZ explants}

For the animal cap explants, mRNAs or a morpholino oligonucleotide were coinjected with 0.5 pg activin mRNA into the animal pole of two-cell embryos. The animal cap was dissected manually from stage 9 embryos. For DMZ explants, mRNA or a morpholino oligonucleotide were injected into the two dorsal blastomeres of four-cell embryos. Explants were isolated at stage $10+$. These explants were cultured in $0.1 \%$ BSA $/ 1 \times$ Steinberg's solution until sibling embryos reached stage 17 . The procedure for observing cells during convergent extension movements was basically according to Wallingford et al. (2000) with some modifications. Explants were isolated at stage 10+ and cultured in $1 \times$ Steinberg's solution on a cover glass coated with fibronectin. The explants were observed by laser-scanning confocal microscopy.

\section{Immunoprecipitation and Western blotting}

HEK293T cells were transiently transfected with the indicated constructs using Lipofectamine Plus (Invitrogen). Cell lysates were prepared in PBS containing $0.1 \%$ Triton-X100, $20 \mathrm{mM}$ $\mathrm{NaF}, 0.5 \mathrm{mM}$ PMSF, and a $1 / 200$ volume of protease inhibitor cocktail (\#P8340, Sigma), and spun at 15,000g for $10 \mathrm{~min}$. The indicated antibodies were added to the supernatants, and incubated at $4^{\circ} \mathrm{C}$ overnight. Protein A/G agarose (\#SC-2003, Santa Cruz Biotechnology) was added, and the mixture was incubated for $1 \mathrm{~h}$ in a tumbling mixer. The agarose beads were washed five times with the lysis buffer. The antibodies used for immunoprecipitation and Western blotting were anti-myc 9E1 (Boehringer Mannheim), anti-Flag monoclonal M2 (Sigma), and antiGFP (\#598, Molecular Biological Laboratories) antibodies.

\section{JNK assay}

mRNA encoding GAL4 (DBD)-tagged c-Jun (100 pg) was injected into two-cell embryos. The animal caps were isolated at stage 10 and smashed by pipetting in sample buffer for SDS-PAGE. These samples were boiled and fractionated by SDS-PAGE. Western blotting was performed using anti-GAL4 (DBD; \#SC510, Santa Cruz Biotechnologyl and anti-phospho-c-Jun (\#9261S, Cell Signaling) antibodies.

\section{Acknowledgments}

We thank Dr. Eisuke Nishida for the MKK7 plasmid and helpful advice, Dr. Atsushi Miyawaki for the Venus plasmid, Dr. Masazumi Tada for the c-Jun plasmid and protocol for the JNK assay, Dr. Richard Harland for the Xdsh plasmids, Dr. Fiona Watt for the MZ15 antibody, and Dr. Junko Miura for comments on the manuscript. We are grateful to all the members of Dr. Ueno's laboratory for their kind support. This work was supported by grants from the Ministry of Education, Science and Culture of Japan to N.U. and N.K.

The publication costs of this article were defrayed in part by payment of page charges. This article must therefore be hereby marked "advertisement" in accordance with 18 USC section 1734 solely to indicate this fact.

\section{References}

Adler, P.N. 2002. Planar signaling and morphogenesis in Drosophila. Dev. Cell 2: 525-535.

Axelrod, J.D. 2001. Unipolar membrane association of Dishevelled mediates Frizzled planar cell polarity signaling. Genes \& Dev. 15: 1182-1187.

Axelrod, J.D., Miller, J.R., Shulman, J.M., Moon, R.T., and Perrimon, N. 1998. Differential recruitment of Dishevelled provides signaling specificity in the planar cell polarity and Wingless signaling pathways. Genes \& Dev. 12: 2610-2622.

Baum, E.Z. and Bebernitz, G.A. 1990. K-ras oncogene expression in Xenopus laevis. Oncogene 5: 763-767.

Bell, R.M. and Burns, D.J. 1991. Lipid activation of protein kinase C. J. Biol. Chem. 266: 4661-4664.

Boutros, M. and Mlodzik, M. 1999. Dishevelled: At the crossroads of divergent intracellular signaling pathways. Mech. Dev. 83: 27-37.

Boutros, M., Paricio, N., Strutt, D.I., and Mlodzik, M. 1998. Dishevelled activates JNK and discriminates between JNK pathways in planar polarity and wingless signaling. Cell 94: 109-118.

Brannon, M. and Kimelman, D. 1996. Activation of Siamois by the Wnt pathway. Dev. Biol. 180: 344-347.

Cadigan, K.M. and Nusse, R. 1997. Wnt signaling: A common theme in animal development. Genes \& Dev. 11:3286-3305.

Carnac, G., Kodjabachian, L., Gurdon, J.B., and Lemaire, P. 
1996. The homeobox gene Siamois is a target of the Wnt dorsalisation pathway and triggers organiser activity in the absence of mesoderm. Development 122: 3055-3065.

Chen, K.H., Peng, Z.G., Lavu, S., and Kung, H.F. 1988. Molecular cloning and sequence analysis of two distinct types of Xenopus laevis protein kinase C. Second Messengers Phosphoproteins 12: 251-260.

Cohen, E.D., Mariol, M.C., Wallace, R.M., Weyers, J., Kamberov, Y.G., Pradel, J., and Wilder, E.L. 2002. DWnt4 regulates cell movement and focal adhesion kinase during Drosophila ovarian morphogenesis. Dev. Cell 2: 437-448.

Diiane, A., Riou, J., Umbhauer, M., Boucaut, J., and Shi, D. 2000. Role of frizzled 7 in the regulation of convergent extension movements during gastrulation in Xenopus laevis. Development 127: 3091-3100.

Habas, R., Dawid, I.B., and He, X. 2003. Coactivation of Rac and Rho by Wnt/Frizzled signaling is required for vertebrate gastrulation. Genes \& Dev. 17: 295-309.

Harland, R.M. 1991. In situ hybridization: An improved wholemount method for Xenopus embryos. Methods Cell Biol. 36: 685-695.

Heisenberg, C.P., Tada, M., Rauch, G.J., Saude, L., Concha, M.L., Geisler, R., Stemple, D.L., Smith, J.C., and Wilson, S.W. 2000. Silberblick/Wnt11 mediates convergent extension movements during zebrafish gastrulation. Nature 405: 76-81.

Kemp, B.E., Parker, M.W., Hu, S., Tiganis, T., and House, C. 1994. Substrate and pseudosubstrate interactions with protein kinases: Determinants of specificity. Trends Biochem. Sci. 19: 440-444.

Kikkawa, U., Kishimoto, A., and Nishizuka, Y. 1989. The protein kinase $\mathrm{C}$ family: Heterogeneity and its implications. Annu. Rev. Biochem. 58: 31-44.

Kintner, C. and Brockes, J. P. 1984. Monoclonal antibodies identify blastemal cells derived from differentiating muscle in newt limb regeneration. Nature 308: 67-69.

Kuhl, M. 2002. Noncanonical Wnt signaling in Xenopus: Regulation of axis formation and gastrulation. Semin. Cell Dev. Biol. 13: 243-249.

Kuhl, M., Sheldahl, L.C., Park, M., Miller, J.R., and Moon, R.T. 2000. The Wnt/Ca ${ }^{2+}$ pathway: A new vertebrate Wnt signaling pathway takes shape. Trends Genet. 16: 279-283.

Kuhl, M., Geis, K., Sheldahl, L.C., Pukrop, T., Moon, R.T., and Wedlich, D. 2001. Antagonistic regulation of convergent extension movements in Xenopus by Wnt/ $\beta$-catenin and Wnt/ $\mathrm{Ca}^{2+}$ signaling. Mech. Dev. 106: 61-76.

Kurata, T. and Ueno, N. 2003. Xenopus Nbx, a novel NK-1 related gene essential for neural crest formation. Dev. Biol. 257: 30-40.

Kurata, T., Nakabayashi, J., Yamamoto, T.S., Mochii, M., and Ueno, N. 2001. Visualization of endogenous BMP signaling during Xenopus development. Differentiation 67: 33-40.

Li, W., Michieli, P., Alimandi, M., Lorenzi, M.V., Wu, Y., Wang, L.H., Heidaran, M.A., and Pierce, J.H. 1996. Expression of an ATP binding mutant of PKC- $\delta$ inhibits Sis-induced transformation of NIH3T3 cells. Oncogene 13: 731-737.

Liu, T., DeCostanzo, A.J., Liu, X., Wang, H., Hallagan, S., Moon, R.T., and Malbon, C.C. 2001. G protein signaling from activated rat frizzled-1 to the $\beta$-catenin-Lef-Tcf pathway. Science 292: 1718-1722.

Liu, X., Liu, T., Slusarski, D.C., Yang-Snyder, J., Malbon, C.C., Moon, R.T., and Wang, H. 1999. Activation of a frizzled-2/ $\beta$-adrenergic receptor chimera promotes Wnt signaling and differentiation of mouse F9 teratocarcinoma cells via Galphao and Galphat. Proc. Nat1. Acad. Sci. 96: 14383-14388.

Luo, Z.G., Wang, Q., Zhou, J.Z., Wang, J., Luo, Z., Liu, M., He,
X., Wynshaw-Boris, A., Xiong, W.C., Lu, B., et al. 2002. Regulation of AChR clustering by Dishevelled interacting with MuSK and PAK1. Neuron 35: 489-505.

McKendry, R., Hsu, S.C., Harland, R.M., and Grosschedl, R. 1997. LEF-1/TCF proteins mediate wnt-inducible transcription from the Xenopus nodal-related 3 promoter. Dev. Biol. 192: $420-431$.

Medina, A. and Steinbeisser, H. 2000. Interaction of Frizzled 7 and Dishevelled in Xenopus. Dev. Dyn. 218: 671-680.

Medina, A., Reintsch, W., and Steinbeisser, H. 2000. Xenopus frizzled 7 can act in canonical and noncanonical Wnt signaling pathways: Implications on early patterning and morphogenesis. Mech. Dev. 92: 227-237.

Moriguchi, T., Kawachi, K., Kamakura, S., Masuyama, N., Yamanaka, H., Matsumoto, K., Kikuchi, A., and Nishida, E. 1999. Distinct domains of mouse dishevelled are responsible for the c-Jun $\mathrm{N}$-terminal kinase/stress-activated protein kinase activation and the axis formation in vertebrates. J. Biol. Chem. 274: 30957-30962.

Nagai, T., Ibata, K., Park, E.S., Kubota, M., Mikoshiba, K., and Miyawaki, A. 2002. A variant of yellow fluorescent protein with fast and efficient maturation for cell-biological applications. Nat. Biotechnol. 20: 87-90.

Newton, A.C. 1997. Regulation of protein kinase C. Curr. Opin. Cell Biol. 9: 161-167.

Nieukoop, P.D. and Faber, J. 1994. Normal Table of Xenopus laevis (Daudin), pp. 163-188. Garland Publishing, Inc., New York.

Nishizuka, Y. 1995. Protein kinase C and lipid signaling for sustained cellular responses. FASEB J. 9: 484-496.

Orr, J.W. and Newton, A.C. 1994. Intrapeptide regulation of protein kinase C. J. Biol. Chem. 269: 8383-8387.

Otte, A.P. and Moon, R.T. 1992. Protein kinase C isozymes have distinct roles in neural induction and competence in Xenopus. Cell 68: 1021-1029.

Otte, A.P., Koster, C.H., Snoek, G.T., and Durston, A.J. 1988. Protein kinase C mediates neural induction in Xenopus laevis. Nature 334: 618-620.

Pandur, P., Lasche, M., Eisenberg, L.M., and Kuhl, M. 2002. Wnt-11 activation of a noncanonical Wnt signalling pathway is required for cardiogenesis. Nature 418: 636-641.

Rauch, G.J., Hammerschmidt, M., Blader, P., Schauerte, H.E., Strahle, U., Ingham, P.W., McMahon, A.P., and Haffter, P. 1997. Wnt5 is required for tail formation in the zebrafish embryo. Cold Spring Harb. Symp. Quant. Biol. 62: 227-234.

Rothbacher, U., Laurent, M.N., Deardorff, M.A., Klein, P.S., Cho, K.W., and Fraser, S.E. 2000. Dishevelled phosphorylation, subcellular localization and multimerization regulate its role in early embryogenesis. EMBO J. 19: 1010-1022.

Sheldahl, L.C., Park, M., Malbon, C.C., and Moon, R.T. 1999. Protein kinase $\mathrm{C}$ is differentially stimulated by Wnt and Frizzled homologs in a G-protein-dependent manner. Curr. Biol. 9: 695-698.

Shih, J. and Keller, R. 1992. Cell motility driving mediolateral intercalation in explants of Xenopus laevis. Development 116: 901-914.

Slusarski, D.C., Corces, V.G., and Moon, R.T. 1997a. Interaction of Wnt and a Frizzled homologue triggers G-proteinlinked phosphatidylinositol signalling. Nature 390:410413.

Slusarski, D.C., Yang-Snyder, J., Busa, W.B., and Moon, R.T. 1997b. Modulation of embryonic intracellular $\mathrm{Ca}^{2+}$ signaling by Wnt-5A. Dev. Biol. 182: 114-120.

Smith, J.C. and Watt, F.M. 1985. Biochemical specificity of Xenopus notochord. Differentiation 29: 109-115.

Smith, W.C. and Harland, R.M. 1991. Injected Xwnt-8 RNA acts 
early in Xenopus embryos to promote formation of a vegetal dorsalizing center. Cell 67: 753-765.

Suetsugu, S., Miki, H., and Takenawa, T. 2002. Spatial and temporal regulation of actin polymerization for cytoskeleton formation through Arp2/3 complex and WASP/WAVE proteins. Cell Motil. Cytoskeleton 51: 113-122.

Sun, T.Q., Lu, B., Feng, J.J., Reinhard, C., Jan, Y.N., Fantl, W.J., and Williams, L.T. 2001. PAR-1 is a Dishevelled-associated kinase and a positive regulator of Wnt signalling. Nat. Cell Biol. 3: 628-636.

Tada, M. and Smith, J.C. 2000. Xwnt11 is a target of Xenopus Brachyury: Regulation of gastrulation movements via Dishevelled, but not through the canonical Wnt pathway. Development 127: 2227-2238.

Tada, M., Concha, M.L., and Heisenberg, C.P. 2002. Noncanonical Wnt signalling and regulation of gastrulation movements. Semin. Cell Dev. Biol. 13: 251-260.

Vielhaber, E. and Virshup, D.M. 2001. Casein kinase I: From obscurity to center stage. IUBMB Life 51: 73-78.

Wallingford, J.B., Rowning, B.A., Vogeli, K.M., Rothbacher, U., Fraser, S.E., and Harland, R.M. 2000. Dishevelled controls cell polarity during Xenopus gastrulation. Nature 405: 8185.

Wallingford, J.B., Fraser, S.E., and Harland, R.M. 2002. Convergent extension: The molecular control of polarized cell movement during embryonic development. Dev. Cell 2: 695-706.

Weaver, A.M., Young, M.E., Lee, W.-L., and Cooper, J.A. 2003. Integration of signals to the Arp2/3 complex. Curr. Op. Cell Biol. 15: 23-30.

Wharton Jr., K.A. 2003. Runnin' with the Dvl: Proteins that associate with Dsh/Dvl and their significance to Wnt signal transduction. Dev. Biol. 253: 1-17.

Willert, K., Brink, M., Wodarz, A., Varmus, H., and Nusse, R. 1997. Casein kinase 2 associates with and phosphorylates dishevelled. EMBO T. 16: 3089-3096.

Wilson, P. and Keller, R. 1991. Cell rearrangement during gastrulation of Xenopus: Direct observation of cultured explants. Development 112: 289-300.

Winklbauer, R., Medina, A., Swain, R.K., and Steinbeisser, H. 2001. Frizzled-7 signalling controls tissue separation during Xenopus gastrulation. Nature 413: 856-860.

Yamamoto, T.S., Takagi, C., Hyodo, A.C., and Ueno, N. 2001. Suppression of head formation by Xmsx-1 through the inhibition of intracellular nodal signaling. Development 128: 2769-2779.

Yamanaka, H., Moriguchi, T., Masuyama, N., Kusakabe, M., Hanafusa, H., Takada, R., Takada, S., and Nishida, E. 2002. JNK functions in the noncanonical Wnt pathway to regulate convergent extension movements in vertebrates. EMBO Rep. 3: 69-75.

Yanagawa, S., van Leeuwen, F., Wodarz, A., Klingensmith, J., and Nusse, R. 1995. The dishevelled protein is modified by wingless signaling in Drosophila. Genes \& Dev. 9: 10871097.

Yang-Snyder, J., Miller, J.R., Brown, J.D., Lai, C.J., and Moon, R.T. 1996. A frizzled homolog functions in a vertebrate Wnt signaling pathway. Curr. Biol. 6: 1302-1306.

Zhang, G., Kazanietz, M.G., Blumberg, P.M., and Hurley, J.H. 1995. Crystal structure of the cys 2 activator-binding domain of protein kinase $\mathrm{C} \delta$ in complex with phorbol ester. Cell 81: 917-924. 


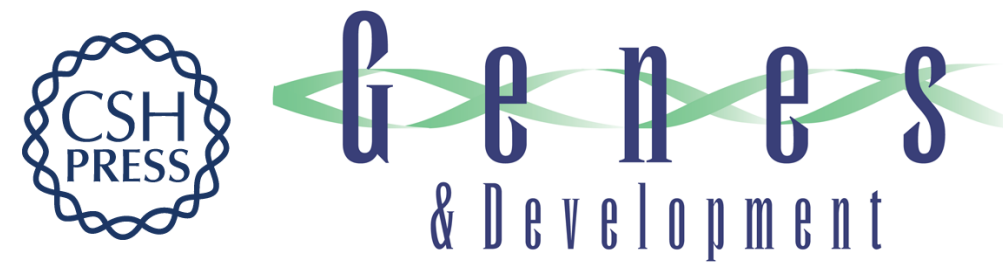

\section{PKC $\delta$ is essential for Dishevelled function in a noncanonical Wnt pathway that regulates Xenopus convergent extension movements}

Noriyuki Kinoshita, Hidekazu lioka, Akira Miyakoshi, et al.

Genes Dev. 2003, 17:

Access the most recent version at doi:10.1101/gad.1101303

References

This article cites 63 articles, 19 of which can be accessed free at:

http://genesdev.cshlp.org/content/17/13/1663.full.html\#ref-list-1

License

Email Alerting

Receive free email alerts when new articles cite this article - sign up in the box at the top

Service right corner of the article or click here.

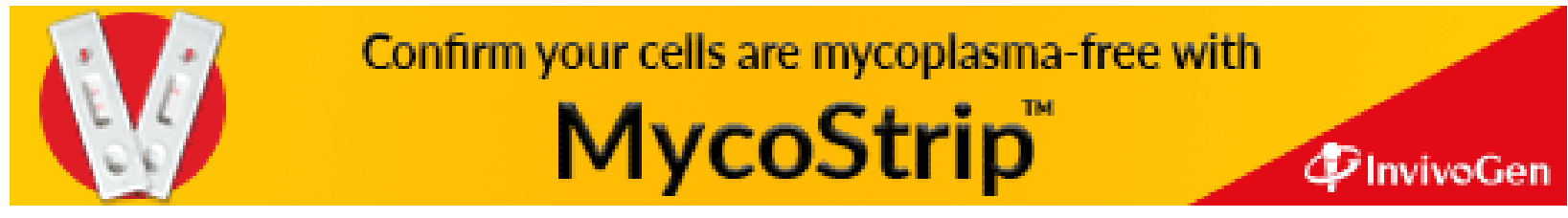

